Case Report

\title{
UNUSUAL PRESENTATION OF SOLITARY BONE CYST - A CASE REPORT
}

\begin{abstract}
Vidya Ajila', Gopakumar R. ${ }^{2}$, Shruthi Hegde ${ }^{3}$, Subhas Babu ${ }^{4} \&$ Harini $\mathbf{K}^{5}$
${ }^{1}$ Reader, ${ }^{3}$ Lecturer, ${ }^{4}$ Professor \& HOD, Department of Oral M edicine \& Radiology, ${ }^{5}$ Lecturer, Department of Periodontics A.B. Shetty Memorial Institute of Dental Sciences, Nitte University, Mangalore, ${ }^{2} \mathrm{HOD}$, New Horizon Dental College and Research Institute, Bilaspur, Chattisgarh, INDIA

Correspondence:

Vidya Ajila

Reader, Department of Oral M edicine \& Radiology, A.B. Shetty Memorial Institute of Dental Sciences, Nitte University, Deralakatte, Mangalore 575 018, India. M obile : +91 9483336155 E -mail : ajila_v@yahoo.com

Abstract:

Solitary bone cyst, also known as traumatic bone cyst or idiopathic bone cyst, is a bony cavity with no epithelial lining and no infection, containing fluid and small amounts of tissue. Clinically these lesions are usually asymptomatic and detected accidentally on routine radiographic examination. Normally, they are empty cavities sometimes having a thin lining of connective tissue without epithelium. They may contain serosanguinous fluid, clots, erythrocytes, fibrin and giant cells. In this report, we present a case of solitary bone cyst in the anterior mandible which was asso ciated with pain .
\end{abstract}

Keywords: Solitary bone cyst, Traumatic bone cyst, bone cavity

\section{Introduction:}

Solitary bone cyst (SBC) is a non neoplastic lesion defined by the WHO as 'an intraosseous cyst having a tenuous lining of connective tissue with no epithelium.[1] Although known by many names such as simple bone cyst, hemorrhagic cyst, idiopathic bone cavity and unicameral bone cyst, the international histological classification of tumours by the WHO recommends use of the term ' solitary bone cyst.' [2] This rare pathology accounts for only $1 \%$ of maxillofacial cysts and tumours. [3]lt is generally an accidental finding during routine radiographic examination. [3,4] In this report, we describe a case of solitary bone cyst which presented to us with pain in the mandibular anterior region.

\section{Case Report :}

A 32 years-old-male reported to the department of oral Access this article online Quick Response Code

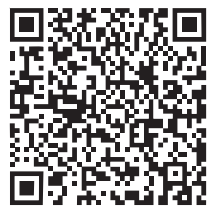
medicine and radiology with a complaint of pain in the mandibular anterior region since one month. The pain was mild in nature and only noticed on palpation. There was no history of trauma. Intraoral examination revealed normal mucosa in the mandibular anterior region with no evidence of bone expansion labially or lingually. No abnormality was observed in the mandibular anterior teeth and all teeth were vital (Figure 1). Anterior mandibular occlusal radiograph showed a roughly cone shaped radiolucency extending from lower left lateral incisor to the first premolar. Radiolucency was not associated with the roots of the teeth and was closer to the lower border of the mandible (Figure 2). The true occlusal radiograph showed a buccally located lesion with an intact buccal cortex and no expansion. There was no thinning of the lower border of the mandible (Figure 3). Panoramic radiography showed a well defined radiolucency measuring about $2 \times 1 \mathrm{cms}$ in size with regular, non corticated borders(Figure 4). Surgical exploration of the area showed an empty bone cavity(Figure 5). The cavity was curetted and tissue obtained submitted for histopathological examination. Sections showed collagenous fibrous tissue with some areas showing bony tissues and extravasated RBCs. There was no evidence of a cystic lining (Figure 6). Based on these features, a diagnosis of solitary bone cyst was made. 


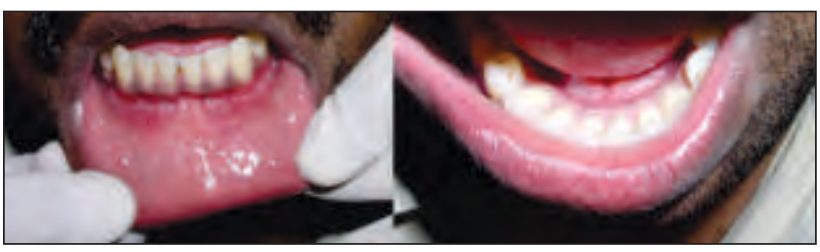

Figure 1: Clinical intraoral photograph showing normal mucosa without cortical expansion.

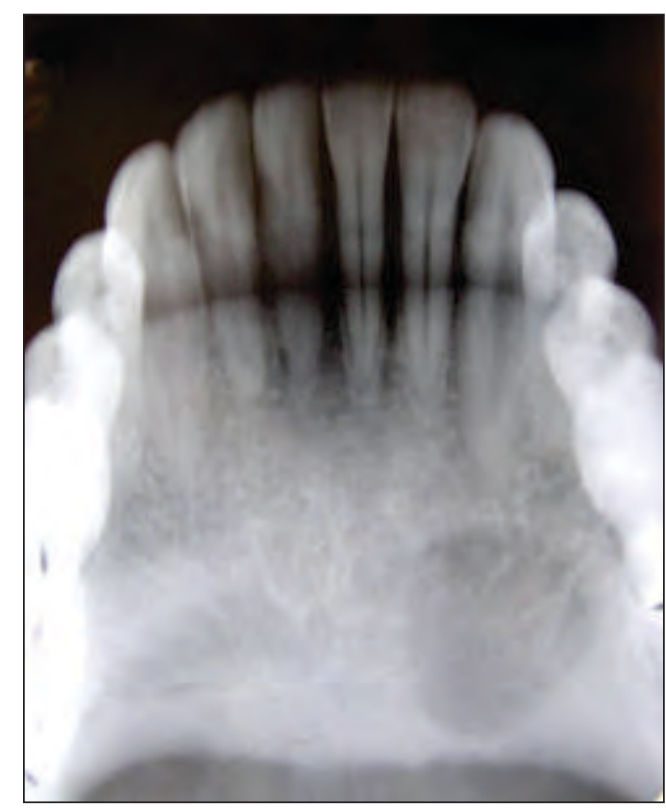

Figure 2: Anterior occlusal radiograph showing cone shaped radiolucency not associated with the roots of the teeth.

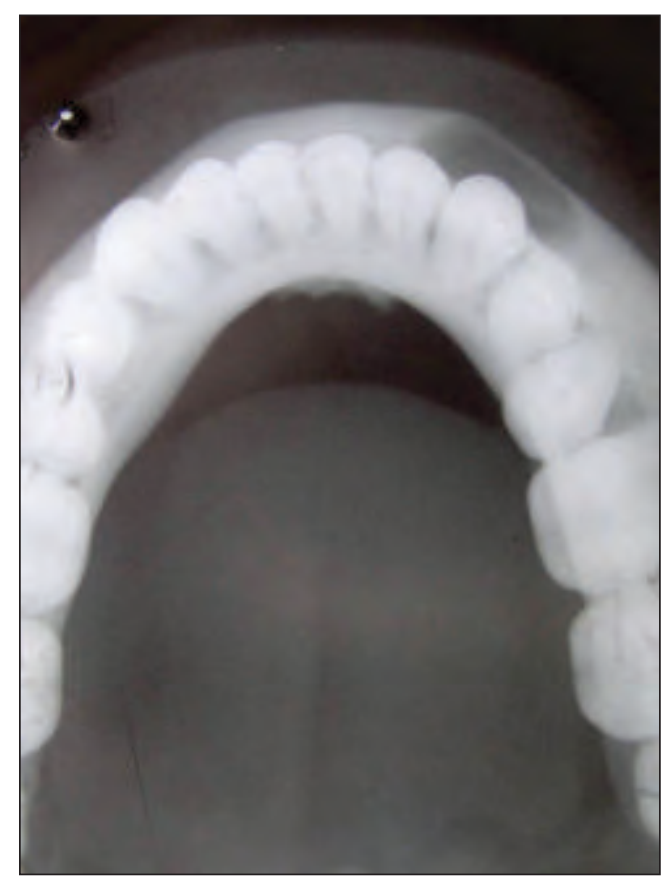

Figure 3: True occlusal radiograph showing radiolucency on the buccal aspect with no buccal or lingual cortical expansion.

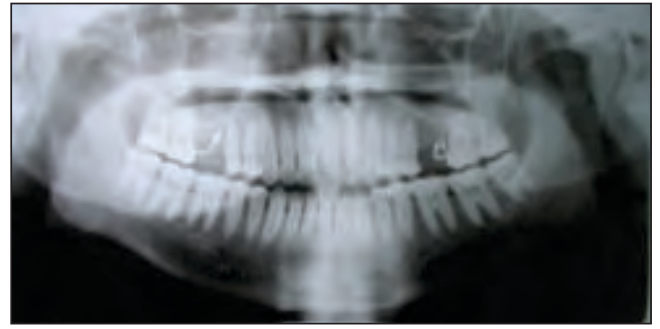

Figure 4: Panoramic radiograph showing cone shaped radiolucency with well defined, non corticated border in left mandibular anterior region.

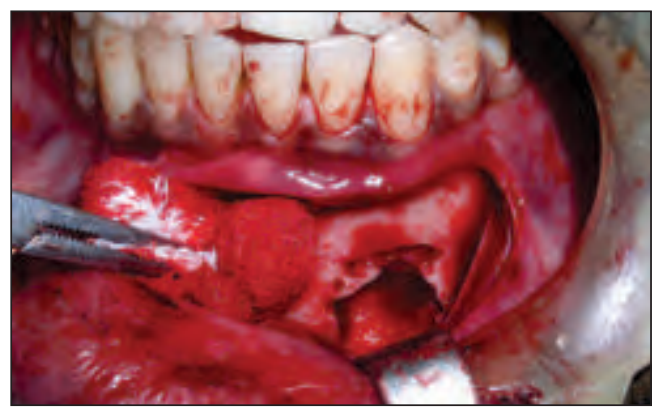

Figure 5: Surgical photograph showing empty cavity in mandibular left anterior region.

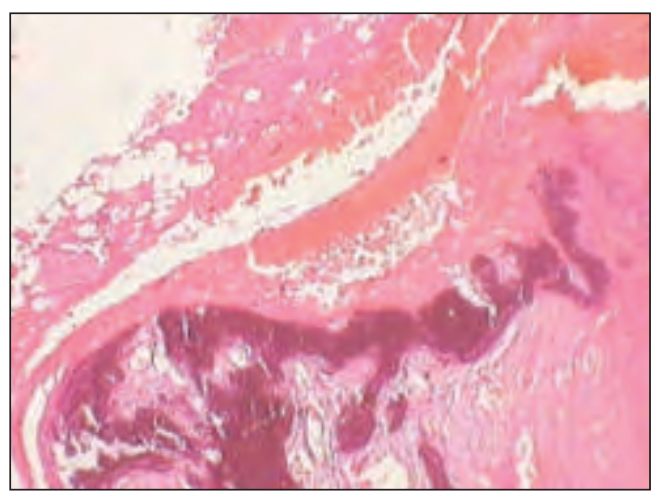

Figure 6: Photomicrograph $(H \& E, 10 X)$ showing collagenous fibrous tissue with no evidence of cystic lining.

\section{Discussion :}

The solitary bone cyst was first described by Lucas in 1929.[1] It is classified as an intraosseous pseudocyst due to the lack of an epithelial lining. [3,5]

The etiopathogenesis of solitary bone cyst is unclear. The various theories proposed include trauma, local alteration of bone metabolism, low grade infection, intraosseous vascular abnormalities and degeneration of bone tumours. $[1,6,7]$ The age of occurrence is usually the second and third decade of life with slight male preponderance or no gender predilection.[7] The present case is of a 32 years 
old male.

Over $90 \%$ of solitary bone cysts are discovered in long bones, notably the proximal humerus and femur.[8] In the gnathic bones, three fourth cases occur in the mandible than the maxilla with the premolar- molar region being a favoured site.[8]We observed the cyst in the mandibular anterior region.

Although usually asymptomatic, one study reported symptoms in $30 \%$ cases.[9] The commonest symptom was pain; other symptoms were swelling, tooth sensitivity, tenderness, hypoesthesia and pathological fracture. $[2,4,10]$ Our case reported tenderness on palpation of the area.

On imaging, SBCs usually appear radiolucent. Radiopaque foci and cloudiness can be observed in few cases. $[7,10]$ The borders may be irregular, well defined, with or without cortication.[7,10] Other features include scalloping or interdigitation between the roots, loss of lamina dura,

\section{References:}

1. Tong AC, Ng IO, Yan BS(2003) Variations in clinical presentations of the simple bone cyst: report of cases.J Oral M axillofac Surg 61:1487-91.

2. Strabbing E.M., Gortzak R.A.Th. , Vinke J.G. , Saridin C.P. , van Merkesteyn J.P.R(2011) An atypical presentation of a solitary bone cyst of the mandibular ramus: A case report. Journal of CranioM axilloFac Surg 39 : e145- 47

3. Velasco I, Cifuentes J, Lobos N, M artín FS(2012) The unusual evolution of a simple bone cyst in the mandible: a case report. J Clin Exp Dent 4: e132-5.

4. MacDonald-Jankowski D. S(1995) Traumatic Bone Cysts in the Jaws of a Hong Kong Chinese Population. Clinical Radiology 50: 787-91

5. de Oliveira JFCD, Barbosa DBM, Pereira LC, Gabrielli M AC, Sarmento VA(2012) Mandibular simple bone cysts: a rare case of bilateral occurrence. BrazJ Otorhinolaryngol 78:134.

6. Perdigão PF, Silva EC, Sakurai E, Soares de Araújo N, Gomez RS(2003) Idiopathic bone cavity: a clinical, radiographic, and histological study. Brj Oral M axillofac Surg 41: 407-9.

7. Mathew R, Omami G, Gianoli D, Lurie A (2012)Unusual cone-beam computerized tomography presentation of traumatic (simple) bone cyst: case report and radiographic analysis. Oral Surg Oral Med Oral Pathol Oral Radiol Endod 113:410-13

8. Nelson BL(2010) Solitary Bone Cyst Head and Neck Pathol 4:208-209

9. Forssell K, Forssell H, Happonen RP, Neva M (1988) Simple bone cyst. Review of the literature and analysis of 23 cases. Int J Oral Maxillofac Surg 17: 21-4

10. Baqain ZH, Jayakrishnan A, Farthing PM , Hardee P (2005)Recurrence of a solitary bone cyst of the mandible: case report. Br J Oral M axillofac Surg 43:333-5

11. Copete M A, Kawamata A, Langlais RP (1998) Solitary bone cyst of the jaws: radiographic review of 44 cases. Oral Surg Oral Med Oral Pathol Oral Radiol Endod 85:221-5. teeth displacement, and root resorption.[10] In the present case, the radiolucency was away from the tooth roots. One study categorised the radiographic morphology of SBC into 4 categories i.e. cone $(64 \%)$; oval $(16 \%)$; irregular (16\%); round (4\%).[11] We observed a cone shaped radiolucency in the mandibular anterior region. Histopathological examination reveals a thin band of vascular fibrous connective tissue without epithelial lining.[2] Treatment consists of surgical exploration and curettage of the bone wall.[10] We followed similar treatment protocol. According to few authors radiographic features such as absence of lamina dura, scalloped margins, nodular bone expansion, internal radioopaque masses and/or multiple cavities were suggestive of increased likelihood of recurrence following treatment.[7] However, none of these features were observed in our case. This report highlights a symptomatic presentation of solitary bone cyst in anterior mandibular region and also describes the clinical and radiographic features. 